\title{
A formação escolar e o componente curricular: a Educação Física em tempos de capitalismo mundial integrado ${ }^{1}$
}

\author{
Rogério Rodrigues ${ }^{2}$
}

\begin{abstract}
RESUMO
O referido ensaio tem como objetivo analisar criticamente a proposição e a implementação do documento preliminar da Base Nacional Comum Curricular da Educação Básica - BNC (BRASIL, 2015). Justifica-se esse ensaio ao considerar que, em relação a qualquer proposta para o ensino da Educação Física na Educação Básica, dever-se-ia partir do pressuposto de que esta disciplina se encontra limitada pelo aspecto da redução do espaço destinado para suas aulas no ambiente escolar e, principalmente, pela formação do profissional da Educação Física pautada, hegemonicamente, na concepção dos conteúdos escolares relativos a esta área do saber direcionados para aspectos esportivos e competitivos. Conclui-se que a peça-chave para a democratização do ensino no campo da cultura corporal e esportiva seria a formação de profissionais de Educação Física como intelectuais da cultura e, portanto, sujeitos capazes de absorver criticamente a implementação de qualquer proposta de ensino.
\end{abstract}

PALAVRAS-CHAVE: Fundamentos da Educação; Educação Básica; Currículo; Educação Física Escolar.

\section{A formation school and curriculum component: Physical} Education in times of capitalism wordl integrated

\begin{abstract}
Such an assay aims to critically analyze the proposition and implementation of the draft document of the Common National Base
\end{abstract}

\footnotetext{
${ }^{1}$ Agradecimentos aos colegas da primeira turma do curso de Educação Física da UNESP de Rio Claro (1984-1987); a Universidade Federal de Itajubá (UNIFEI) e a Faculdade de Educação da Universidade de São Paulo (USP) na supervisão do Pós-doutorado pelo Prof. Dr. Leandro de Lajonquière.

${ }^{2}$ Doutor em Educação (UNICAMP). Docente da Universidade Federal de Itajubá Av. BPS, 1303, Bairro Pinheirinho, Itajubá - MG Caixa Postal 50 CEP: 37500 903. e-mail: rogerio@unifei.edu.br.
} 
Curriculum of Basic Education - BNC (BRASIL, 2015). It justified this test when considering that, in relation to any proposal for the teaching of Physical Education in Basic Education, duty would be to assume that this discipline is limited by the aspect of reducing the space devoted to their classes in school environment, and especially the formation of the professional of Physical Education guided hegemonically in the design of educational content relating to this area of knowledge directed to sporting and competitive aspects. It is concluded that a key to the democratization of education in the field of physical and sports culture would be the formation of Physical Education professionals as culture intellectuals and therefore subject able to critically absorb the implementation of any educational proposal.

KEY-WORDS: Foundations of Education; Basic Education; Curriculum;

School Physical Education.

\section{Introdução: o papel do ensino da Educação Física na educação básica}

Tornou-se senso comum pedagógico a compreensão de que o aparelho escolar deve possuir a função principal de formar o cidadão crítico e participativo. Para tanto, a unidade escolar incorpora como tarefa de fundamental importância a transmissão dos diversos elementos da cultura através do currículo escolar.

Todos aqueles que trabalham no campo educacional compreendem que, no caso específico da unidade de ensino, os diversos saberes difusos na sociedade encontram-se em interface direta e indiretamente com a cultura escolar. Essa relação entre escola e cultura promove a organização e transmissão desses saberes que se encontram elaborados no transcorrer da existência do homem.

Nesse caso, parte-se da hipótese de que a função democrática da escola seria formar o cidadão crítico e participativo ao dar acesso a diversos elementos da cultura e, principalmente, permitir a ele interpretar os diversos saberes presentes na sociedade. 
Portanto, a cidadania é também elemento constituído na formação cultural do sujeito e o aparelho escolar pode desempenhar um papel fundamental no processo de escolarização do sujeito referente ao domínio da cultura letrada.

O letramento da cultura escolar encontra-se presente em diversas disciplinas curriculares e, portanto, a transmissão dos elementos da cultura elaborada na unidade escolar apresenta-se com algum consenso, como, por exemplo, no caso da comunicação e expressão no ensino da língua portuguesa, pode-se encontrar a exigência estabelecida no Plano Nacional da Educação que determina como meta que todos os alunos até oito anos de idade devem se encontrar alfabetizados e isso corresponde ao final da terceira série do ensino fundamental (BRASIL, 2016).

Compreende-se que o processo de alfabetizar é uma linha de corte para o ingresso no campo da cultura escolar. Entretanto, a passagem para a condição de sujeito alfabetizado seria algo para além do fato de ler, pois é preciso que ele possa também interpretar a linguagem escrita, falada e corporal.

Pode-se fazer um paralelo entre esse paradigma de alfabetizar em diversos campos dos saberes com diversas situações, o que pode ser também vivenciado no campo da comunicação e expressão ou em outras áreas do conhecimento. A partir dessa referência, torna-se possível perguntar: o que seria, em termos de educação básica, encontrar-se "alfabetizado" no campo da Educação Física?

Responde-se em parte a essa questão ao afirmar que, no caso do ensino da Educação Física escolar, essa tarefa de alfabetizar realiza-se ao transmitir a cultura e, principalmente, ao permitir a incorporação nos sujeitos de elementos pertencentes à cultura corporal e esportiva. Torna-se evidente compreender o papel do ensino dessa disciplina na educação básica brasileira no sentido de formar o cidadão questionador e participativo como aquele que interpreta criticamente o uso do corpo na modernidade. 
Entretanto, outra parte dessa resposta sobre como formar o cidadão já se encontra dada por outras duas condições fundamentais que instauram os verdadeiros contornos, mais propriamente os determinantes no ensino da Educação Física escolar, como um elemento estruturante que permita ao sujeito compreender criticamente a vida em cidade, mais propriamente interpretar o mundo em que se encontra inserido como sujeito.

De um aspecto prático, os determinantes apresentam-se na formação do profissional da Educação Física e na própria realidade das escolas instauram, no cotidiano escolar, as possibilidades de realizar o ensino dessa disciplina. Em grande parte, os profissionais que atuam nessa área são formados numa concepção de educação do corpo pautada exclusivamente no sujeito biológico e que venha atender à demanda de "aptidão natural" na eficácia do desempenho esportivo. Essa concepção de ensino de Educação Física reduz as possibilidades de sua transmissão, pois grande parte da população brasileira escolar não atende ao estereótipo do sujeito esportivo.

Já em relação às unidades escolares, podem-se encontrar determinadas formas reduzidas nas possibilidades de realizar a Educação Física, em decorrência da arquitetura dos prédios, que diminui cada vez mais os espaços destinados para a atividade física. Em contrapartida, a redução dos espaços destinados para as aulas de Educação Física poderia ser contornada pela criatividade do professor na tarefa de transmitir os conteúdos escolares pertinentes à cultura corporal e esportiva. Entretanto, o processo de precarização do espaço associado à formação esportiva quanto a aspectos competitivos no ensino da Educação Física é algo que destitui a possibilidade de realizar o ensino dessa disciplina na escola.

Compreende-se que a crise no ensino da Educação Física é algo mais amplo que a própria restrição do espaço que atinge a unidade escolar como um todo e, portanto, a unidade escolar apresenta-se como lugar em que os diversos elementos da cultura transparecem-se na precariedade e indica a falta de criatividade e coerência que se constitui na nossa concepção como pressupostos para a formação do pensamento crítico. A repetição destituída 
de sentido e a incoerência no tratamento do conteúdo escolar resultam na ampliação do estado de regressão na transmissão da cultura corporal e esportiva.

O resultado dessa situação no campo escolar é um indicativo de que se reduz o acesso à cultura geral e esse elemento pode ser identificado nas avaliações que ocorrem no âmbito da educação, apontando a precária situação em que ela se encontra de modo geral. No denominado Programme for International Student Assessment - PISA (Programa para Avaliação Internacional de Estudantes), realizado pela Organização para a Cooperação e Desenvolvimento Econômico (OCDE) e implementado no Brasil em 2000, avalia-se o conhecimento em Ciências, Leitura e Matemática dos alunos na idade de 15 anos que estão concluindo o Ensino Fundamental ou cursando o Ensino Médio. Nos exames desse programa, o desempenho dos alunos brasileiros no ensino de Ciências encontra-se nas últimas posições do ranking internacional, ou seja, comparado a diversos países participantes do programa, o Brasil está quase na última colocação, ficando na frente apenas de países como Colômbia, Tunísia, Azerbaijão, Qatar e Quirguistão. Na área específica de Ciências, é possível identificar sérios problemas educacionais, pois

Em ciências, o Brasil obteve o $59^{\circ}$ lugar do ranking com 65 países. Apesar de ter mantido a pontuação (405), o país perdeu seis postos desde o $53^{\circ}$ lugar em 2009. Nessa disciplina, a média dos países da OCDE foi de 501 pontos. [...] No exame de ciências, 55,3\% dos alunos brasileiros alcança apenas o nível 1 de conhecimento, ou seja, são capazes de aplicar o que sabem apenas a poucas situações de seu cotidiano e dar explicações científicas que são explícitas em relação às evidências (SEM AUTOR, 2016).

Nesse caso, a formação escolar da Educação Física pautada na ciência do esporte competitivo constitui-se também em elemento de precarização do profissional dessa disciplina, pois se trata de imitar a aparência sem 
compreender radicalmente os diversos componentes que se encontram presentes na manifestação do esporte de competição. A imitação precária associada à redução dos espaços nas construções destinadas para a atividade física na unidade escolar pela própria estrutura arquitetônica que a escola condiciona reduz a prática da Educação Física na utilização da "quadra poliesportiva" como um espaço alheio ao ambiente escolar. Esse fato manifesta-se por diversas ações governamentais, que a todo o momento vêm reduzindo a oferta dessa disciplina na grade curricular.

Já se convencionou que a "quadra poliesportiva" é o espaço único destinado e permitido para a realização da Educação Física. O grande prejuízo é que nesse espaço reduzido do "poliesportivo" o que prevalece é o elemento contrário, pois o que se manifesta é o monoesportivo na prática do jogo do futebol. Diga-se de passagem: em grande maioria, reduz-se o ensino do futebol a um verdadeiro "rachão", a uma "pelada", a um "arranca toco", enfim, a uma negação por completo da presença do intelectual da Educação Física na quadra como espaço de reflexão sobre a cultura corporal. Nesse ponto, constitui-se a seguinte questão: se não trata de formar o sujeito no campo da cultura corporal, o que de fato estaria sendo a função social dessa transmissão de saber na unidade escolar?

Para responder a esse questionamento, levou-se em consideração que o aspecto teórico no ensino da Educação Física justifica-se como uma tentativa de estabelecer diversas proposições para a qualidade desta no campo escolar e no caso específico o documento preliminar da Base Nacional Comum Curricular da Educação Básica - BNC (BRASIL, 2015), que define um conjunto de ações para serem realizadas na unidade escolar, em se tratando da reflexão sobre o ensino da Educação Física.

Sobre essa proposição teórica sobre a transmissão do saber no campo da Educação Física, de modo geral, pode-se compreender que a proposta do BNC atende à demanda dos processos de escolarização no sentido de preencher uma lacuna no campo da cultura corporal e esportiva. Entretanto, o que deve ser avaliado é qual o direcionamento na formação do sujeito no 
campo da cultura em interface com a Educação Física. Portanto, trata-se de analisar o quanto e, principalmente, como o ensino da Educação Física encontra-se atrelado ou distanciado da lógica imperativa do Capitalismo Mundial Integrado - CMI (GUATTARI, 1990), no sentido de formar um tipo de sujeito apto para o consumo alienado na prática do esporte.

A lógica do capital constitui-se em ampliar o consumo de coisas e, portanto, em aumentar a produção numa sociedade não planejada em que a finalidade central seria a obtenção do lucro. O resultado dessa lógica seria a concentração de renda daqueles que possuem os meios de produção e, principalmente, a péssima distribuição da riqueza produzida. O uso do corpo na lógica do capital ao atender a essa demanda não planejada seria condicionar o sujeito ao consumo de coisas e inclusive do espetáculo esportivo como objeto de consumo como elemento impróprio ao pensamento no campo da cultura.

Trata-se de destacar a crítica ao CMI (GUATTARI, 1990) de que nos posicionamos na concepção de mundo que entende que formar o cidadão questionador e participativo seja um mecanismo de resistência a algo que gire em torno de somente formar o sujeito dócil no sentido de atender às exigências do mercado de ser produtor e consumidor.

Compreende-se a interface do sujeito no campo da cultura e em outras esferas e isso se apresenta na contraposição sobre como o campo escolar absorve a concepção de cultura como algo profundamente reacionário, pois ela seria

[...] uma maneira de separar atividades semióticas (atividades de orientação no mundo social e cósmico) em esferas, às quais os homens são remetidos. Isoladas, tais atividades são padronizadas, instituídas potencial ou realmente capitalizadas para o modo de semiotização dominante - ou seja, elas são cortadas de suas realidades políticas (GUATTARI \& ROLNIK, 2005, 21). 
A proposição do ensino dos elementos da cultura estruturado no currículo escolar é uma abstração do real no sentido de interpretá-los na lógica da hegemonia dominante. Nesse aspecto, a cultura se (re)apresenta como elemento da reificação e o que prevalece são os pressupostos dominantes. Pergunta-se no caso específico da proposta do BNC: ela possibilita alguma ruptura com a hegemonia do capital?

$\mathrm{O}$ que se pode constatar na referida proposta é que ainda prevalece a compreensão pautada na premissa do educar na base do pronunciamento do “mestre explicador" (RANCIÈRE, 2002).

Apesar de todo esforço na proposta da BNC de serem usados verbos como: "experimentar", "desfrutar", "formular", "realizar", "reconhecer", "compreender", "identificar", "refletir", "construir" e "contribuir" (BRASIL, 2015), ela ainda compreende o sujeito como alguém passivo, no sentido de que seja depositado nele um conjunto de informações que devem ser memorizadas e representadas para atender à demanda de que o sujeito aprendeu. Em outras palavras, ainda concebe-se o espaço escolar como lugar reservado e único para a transmissão de conjunto de saber, pois a própria estrutura organizacional opera como elemento para instaurar outros elementos e modelos e que impõe como verdade o que seria o ensino da Educação Física no período da Educação Básica. Portanto, a pergunta central seria: como identificar na Educação Física escolar, quanto ao uso do corpo, elementos de resistência à hegemonia do capital e, principalmente, à ruptura com os modos de consumo de coisas no campo do fenômeno esportivo?

O que se constata é que cada vez que retorno em quadra de aula o meu encontro são com alunos com suas vestimentas, modos de falar, corte de cabelo, técnicas de corpo que se modelam como elementos amplamente imitativos do fenômeno esportivo. Isso me leva a concluir que a ruptura com o CMI (GUATTARI, 1990) é uma luta de cada dia e talvez isso seja um dos grandes motivos pelos quais os alunos devam ir todos os dias à escola como longo processo temporal de inserir o sujeito no campo da cultura. 


\section{Discussão: o componente curricular em Educação Física - desafios e resistência para a democratização da cultura corporal e esportiva na unidade escolar}

Pensar na democratização do acesso à escola é também analisar como os conteúdos escolares são transmitidos. Aqueles que têm pouco trânsito no ambiente escolar e são pouco conhecedores sobre o cotidiano do ensino da Educação Física escolar podem compreender que ocorre uma redução do ensino sobre a prática corporal a elementos cada vez mais rudimentares e até podem observar a completa ausência do ensino da Educação Física.

Por diversos anos trabalhando como educador no campo da Educação Física, pude presenciar uma total falta de critério na transmissão da cultura corporal e esportiva. Inclusive, é possível encontrar alunos no ensino superior - ou seja, que passaram pelas aulas de Educação Física durante os quatorzes anos da Educação Básica (Educação Infantil, Ensino Fundamental e Ensino Médio) - que se apresentam como verdadeiros analfabetos sobre os elementos da cultura corporal e esportiva.

Nesse caso, pode-se pontuar o mérito da proposta BNC de buscar sistematizar e organizar os elementos que devem ser trabalhados na Educação Básica em se tratando do ensino da Educação Física escolar. Contudo, torna-se necessário compreender os diversos elementos que se apresentam no cotidiano escolar que fazem a cultura corporal e esportiva, quando ela ocorre, algo que se representa como pequeno esboço mal feito sobre os cuidados do corpo ou da prática do esporte. Portanto, é preciso compreender que, na realidade, ocorre, no campo escolar, um fenômeno paradoxal, qual seja: pouco se busca compreender a cultura corporal e esportiva em termos do saber crítico. Simultaneamente, de um lado, ocorre uma hipervalorização dos "cuidados com o corpo" e uma aclamação exacerbada no ufanismo na prática do esporte. Por outro lado, ocorre um completo abandono nos aspectos de transmissão dos conteúdos referentes à Educação Física escolar. Parte-se do pressuposto de que compreender esse 
contraditório pode ser um passo decisivo para implementação da proposta da BNC na Educação Física escolar.

Para se compreender esse paradoxo no campo do ensino da Educação Física escolar, deve-se afirmar que, quanto à cultura corporal e esportiva, a grande parte da população escolar apresenta-se "analfabeta", no sentido de não compreender o significado cultural e científico de fazer as coisas com o corpo. Essa condição produz um tipo de sujeito que se torna pouco resistente ao consumo de certos estigmas corporais, produtos e eventos esportivos.

Compreende-se que, no limite, a referida proposta do BNC deveria tocar diretamente nesta "ferida", ao propor uma crítica contundente sobre os modos de fazer as coisas com o corpo. Não basta ser uma proposta que se apresenta como mais uma nova orientação institucional geral e que tende a somente ficar no papel. Para a referida proposta concretizar-se, é de fundamental importância que ela deva ser constituída com a criticidade de compreender que há unidade entre teoria e prática - práxis (VÁZQUEZ, 1977) e que o uso do corpo está diretamente relacionado como uma concepção de mundo e, portanto, as "técnicas de corpo" trazem em suas marcas as sociedades que as produzem (MAUSS, 1974).

Avalia-se que se a proposta para o ensino da Educação Física não atacar diretamente o ponto que impede a democratização do ensino da cultura corporal e esportiva no campo escolar, qualquer tipo de proposição trata-se de mera ilustração para agrupar-se nas estantes das unidades escolares.

Parte-se do pressuposto de que a compreensão dos processos de escolarização deveria se estabelecer como elemento de ruptura com o senso comum pedagógico que invade o campo escolar, e isso seria, de certo modo, romper com o modelo de paradigma educacional do sujeito cognitivo, como algo que também se encontra nas diversas interfaces do campo de ensino da Educação Física. Torna-se possível identificar, nesse campo de ensino, uma exigência de normalização do sujeito, bem como o fato de que esse possa atender à lógica do mercado na hegemonia do CMI (GUATTARI, 1990). Isso 
circunscreve o sujeito como objeto e, portanto, condiciona todas as demais relações em que o educar é informar, o trabalho é produzir e a saúde é comércio.

\begin{abstract}
Não existe, a meu ver, cultura popular e cultura erudita. Há uma cultura capitalista que permeia todos os campos de expressão semiótica. É isso que tento dizer ao evocar os três núcleos semânticos do termo cultura. Não há coisa mais horripilante do que fazer a apologia da cultura popular, ou da cultura proletária, ou sabe-se lá o que do gênero. Há processos de singularização em práticas determinadas e há procedimentos de reapropriação, de recuperação, operados pelos diferentes sistemas capitalísticos. (GUATTARI \& ROLNIK, 2005, 30).
\end{abstract}

O ponto central desse estudo seria compreender se é possível, no fazer pedagógico, que a unidade entre a teoria e a prática produza mecanismos de resistência no campo escolar para além das inscrições oficiais instauradas pela cultura capitalista.

No fazer pedagógico, é preciso construir algo que possa romper com essa lógica de mercado do sujeito informado para o esporte, consumidor de esporte, e que possa pensá-lo numa nova recomposição de força em que prevaleça sua humanidade, em que educar seja troca de experiência humana, o trabalho corporal seja a expressão do intelecto do sujeito e a saúde seja uma tênue recomposição de equilíbrio entre os processos degenerativos e a ampliação da qualidade de vida no campo do social.

Neste caso, pode-se identificar o foco central desse ensaio, que seria reanalisar a proposição, estabelecida em grande parte dos planos de ensino, de formar o sujeito crítico e participativo, que, no caso da $\mathrm{BNC}$, fica pronunciado como estratégia de "[...] possibilitar às novas gerações a preservação e a reconstrução da herança científica e cultural acumulada pela humanidade sob forma de conhecimentos sistematizados" (BRASIL, 2015, p. 95). 
O paradigma de análise para compreender a educação do corpo na modernidade está pautado na compreensão de que, em seu uso, transparece no sujeito a materialidade do seu modo de existir e, portanto, no uso do corpo, encontram-se presentes as interações entre diversas formas de existência do sujeito. Entretanto, os elementos que compõem essa transmissão ocorrem em duas esferas, que seriam as formas conscientes e inconscientes. Essa compreensão sobre a educação do corpo aprofunda-se a partir do conceito de Michel Foucault (1979), que identifica no corpo um lugar em que se trata da realização de uma "[...] estratégia bio-política" (FOUCAULT, 1979, p. 80). Assim, no modo de existir do sujeito no corpo, pode-se compreender que:

O controle da sociedade sobre os indivíduos não se opera simplesmente pela consciência ou pela ideologia, mas começa no corpo, com o corpo. Foi no biológico, no somático, no corporal que, antes de tudo, investiu a sociedade capitalista. O corpo é uma realidade bio-política (FOUCAULT, 1979, p. 80).

Nesse caso, o sujeito tomado pelo uso do corpo encontra-se inscrito com elementos sociais que também produzem no sujeito a singularização do ser sujeito em formas abstratas que engendram as circunstâncias determinadas em que as técnicas do corpo são produzidas (MAUSS, 1974). Dentro desse quadro, fica novamente a seguinte questão: seria possível nas aulas de Educação Física romper ou fazer fissuras com a hegemonia do CMI (GUATTARI, 1990) e instituir outras formas no controle corporal?

Compreende-se que, em parte, esse papel de contra-hegemonia seria o eixo norteador a ser desempenhado pela educação escolar na constituição do sujeito crítico e participativo. Para compreender essa proposta no campo da cultura corporal e esportiva da Educação Física escolar, seria necessário que a referida proposição da BNC estivesse associada à presença do intelectual dessa disciplina, no sentido de instaurar novas formas de pensar à 
concepção de sujeito e, portanto, uma reinterpretação de uso do corpo que ressurja como contraposição "bio-política", que possa estabelecer outra lógica de compreender o sujeito e que realinhe novas possibilidades de inscrição no eixo da Educação Física escolar.

\section{Conclusões: Para um ensino democrático da Educação Física escolar}

No final da década de 1980, mais precisamente no ano de 1986, tive a grande oportunidade de iniciar participação no grupo de estudo do Professor Paulo Ghiraldelli Júnior, ${ }^{3}$ no qual se constituiu uma discussão sobre o papel da Educação Física no campo escolar como elemento para democratizar o acesso à cultura corporal e esportiva. O resultado dessa discussão encontrase, em parte, no livro publicado em 1988 e intitulado "Educação Física Progressista: a pedagogia crítico-social dos conteúdos e a educação física brasileira" (GHIRALDELLI, 1988). Nesse livro, ficou estabelecida a perspectiva teórica do professor de Educação Física no campo escolar:

Particularmente, o profissional da área da Educação Física desenvolve a tarefa de "agente cultural" no âmbito da mais decisiva intimidade, pois atua no sentido de implantar no próprio movimento humano os ditames da cultura. Assim, a denominação do professor de Educação Física como "educador do movimento" assume certa veracidade e, em inúmeros casos, certa tragicidade! Afinal, cabe ao "educador do movimento" a tarefa de engravidar o movimento humano de cultura e, mais precisamente, de uma determinada cultura. Ao professor de Educação Física coube, então, o destino, talvez pouco confortável, de transportar a hegemonia para o conjunto complexo da individualidade humana (GHIRALDELLI, 1988, p. 53).

\footnotetext{
${ }^{3}$ Grande parte da minha formação acadêmica se deve a esse professor, que, no interior da primeira turma do curso de Educação Física da UNESP de Rio Claro, que se encontrava, principalmente, pautado numa concepção de uso do corpo pelos conceitos do reducionismo biológico, tornou-se possível indicar outras formas de leitura sobre a questão do corpo no campo das ciências humanas.
} 
Esse elemento pertinente ao ensino da Educação Física na “[...] tarefa de engravidar o movimento humano de cultura e, mais precisamente, de uma determinada cultura" (GHIRALDELLI, 1988, p. 53) é que torna possível compreender a constituição da subjetividade do sujeito em elementos próprios da formação escolar. Portanto, compreende-se que a função principal das orientações estabelecidas no documento preliminar da Base Nacional Comum Curricular da Educação Básica - BNC (BRASIL, 2015) seria a de estabelecer uma direção na constituição dos processos de subjetivação do sujeito no campo do ensino da Educação Física. Nesse aspecto, a presença do profissional da Educação Física no papel de intelectual seria algo que se consegue interpretar no campo da cultura corporal e esportiva que, tendo como base a produção de subjetividade, compreenda:

[...] o essencial da subjetividade é de ela só se conhecer por fora, em sua própria invenção, e nunca por dentro. Se ela se conhecer por dentro, está morta; se ela for decifrada por fora, então está plena, torna-se, com efeito, objeto; mas ela é objeto em seus resultados, o que nos remete a uma subjetividade que, por sua vez, não é realmente objetivável (SARTRE, 2015, p. 54).

Essa análise sobre a produção da subjetividade é que torna o trabalho de educar o corpo fisicamente algo para além da repetição do movimento corporal. A compreensão de que a subjetividade resulta de produção social amplia o olhar para o documento preliminar da Base Nacional Comum Curricular da Educação Básica - BNC (BRASIL, 2015), e tal compreensão poderia assumir outros contornos, entendendo-se que não se trata mais de avaliar ou validar a competência técnica do referido documento.

O ponto central é saber qual o direcionamento, em termos de concepção de mundo, que se busca ao efetivar a referida proposta no ensino 
de Educação Física escolar. Tendo essa questão da produção da subjetividade como base, há a necessidade de ampliar dois elementos primordiais na junção dessa proposta do BNC, à qual já se fez referência anteriormente neste ensaio, quais sejam: investir em espaços condizentes com a prática da Educação Física escolar e, principalmente, aprimorar a formação dos licenciados em Educação Física escolar. Sem essas contrapartidas, que, em certos termos, beiram o senso comum em termos de política pública, qualquer proposta se tornará vã e não produzirá os seus efeitos pedagógicos no campo escolar.

Essa perspectiva no ensino da educação física centra-se na ideia que o movimento corporal humano está contido por certa historicidade e cabe ao intelectual da Educação Física retratar isso em sua prática educativa, ou seja, falar em "Educação Física" é também fazer uma prática educativa que seja progressista no sentido de estabelecer a criticidade na formação cultural do sujeito. Nesse caso, o trabalho do intelectual da Educação Física é a análise crítica do movimento corporal humano inserido na história das práticas culturais. Portanto,

Um professor de Educação Física, ao planejar suas aulas, deve se perguntar: que conteúdos e habilidades podem ajudar a ser um cidadão participativo? Em que as condições materiais de vida, experiências, conhecimentos, valores afetam o desenvolvimento das aulas? Como a educação do corpo, do movimento e os esportes podem contribuir para o exercício de uma prática social consciente e menos alienada? Por que a Educação Física higienista, militarista, pedagogista ou competitivista não são suficientes ou impróprias para um bom programa de Educação Física e esportes? (LIBÂNEO, 1988. p. 11).

Todos esses anos de trabalho com aquilo que se denomina Educação Física Escolar levaram-me a constatar que a materialização de uma prática educativa progressista está na dependência direta de uma sociedade que 
possua em suas raízes uma vertente democrática. Em muitas vezes, obtivemos pequenos pontos de avanço efetivo para a compreensão do que seja a realização de um trabalho pautado na realização de uma práxis educativa. Penso que este seja o momento de tornar atual esse debate anterior, ou seja, a possibilidade de realizarmos uma análise do sentido da nossa própria formação cultural no campo da Educação Física/Educação do Corpo.

O que se tem hoje é que no interior da escola estreita-se cada vez mais o caminho para a plena burocratização da prática educativa a ponto de impedir a livre circulação do pensamento crítico. O lugar da plena realização do desejo em aprender acaba se constituindo por instituições alternativas que cumprem o papel de inclusão de sujeitos que não encontram na escola o pleno reconhecimento de sua condição de vida e, principalmente, de sujeito.

Discutir esses pontos é apontar para a questão crucial referente ao nosso papel de educador numa sociedade que possui em seu interior as contradições das classes sociais. Portanto, apontar para a questão do papel que a Educação Física vem assumindo neste processo de escolarização, mais propriamente, seria questionar as condições necessárias para a realização de uma efetiva Educação Física Progressista inserida numa sociedade contraditória em si. A pergunta central para retomar o ensino da educação física no campo escolar é: qual o caminho a seguir para a plena realização de uma prática educativa progressista que possa favorecer a produção do sujeito saudável para além dos determinantes do biológico?

Temos um corpo determinado pelo uso como instrumento, ou seja, vive-se uma inversão, o instrumento passa a ter vida e o corpo passa a ser morto. Em muitos casos, utilizamos desse recurso quando precisamos submeter o corpo a práticas exaustivas, nas quais o que mais treinamos é a anulação do corpo e a sua plena subordinação à palavra, ou seja, uma ordem é uma ordem e deve ser cumprida e não questionada. Sentimos isso na pele quando é exigida do corpo uma ação não correspondida, o que se apresenta nas situações de combate e até nas práticas esportivas competitivas. O corpo 
passa a ser treinado nem tanto para o condicionamento físico e sim para o condicionamento psicológico, ou seja, um corpo que atua cegamente para atingir determinado objetivo. Isso seria um abandono da teoria cartesiana para o qual a relação entre corpo e alma colocaria a razão no comando (DESCARTES, 1974). Para tanto, é preciso que se tenham condições de estudo e elaboração de uso do corpo, isto é, que a Educação Física seja exercida de modo sistemático e não como algo casual, quando não se tem nada para fazer para passar o tempo. Esse modo de compreender a Educação Física é um ponto de destaque para o lugar que ela deve ocupar nas instituições de ensino e isso é, de certo modo, a nossa defesa do seu ensino e, principalmente, a democratização da cultura corporal em nossa sociedade e na produção do sujeito saudável no campo da cultura.

Penso que em grande parte a oportunidade de estar aqui e escrever algo sobre o movimento corporal humano pautado na teoria crítica acaba por despertar o sentimento de que temos ainda a possibilidade de nos opormos à hegemonia de uma ciência estritamente racionalista, que insiste em tratar o sujeito como coisa e, principalmente, a esperança que se possa consolidar na educação brasileira o ensino da Educação Física que esteja para além dos determinantes do capital.

\section{Referencias Bibliográficas}

BRASIL. Base Nacional Comum Curricular (BNC). Ministério da Educação. 2015. BRASIL. Plano Nacional de Educação - 2011 a 2020 - Metas e Estratégias. Disponível em: http://fne.mec.gov.br/images/pdf/notas tecnicas_pne_2011_2020.pdf $>$, acessado em 23 de março de 2016.

DESCARTES, René. Meditações. Trad. J. Guinsburg e Bento Prado Júnior. São Paulo: Abril Cultural. 1974.

FOUCAULT, Michel. Microfísica do Porder. Trad. Roberto Machado. Rio de Janeiro: Grall, 1979. 
GHIRALDELLI, Paulo. Educação Física Progressista: a pedagogia crítico-social dos conteúdos e a educação física brasileira.São Paulo: Edições Loyola, 1988.

GUATTARI, Félix. As três ecologias. Trad. Maria Cristina F. Bittencourt. Campinas: Papirus, 1990.

GUATTARI, Félix \& ROLNIK, Suely. Micropolítica: cartografias do desejo. $7^{\mathrm{a}}$ Edição. Petrópolis: Vozes, 2005.

LIBÂNEO, José Carlos. Prefácio. In: GHIRALDELLI Jr, Paulo. Educação Física Progressista: a pedagogia crítico-social dos conteúdos e a educação física brasileira. São Paulo: Edições Loyola, 1988.

MAUSS, Marcel. As técnicas corporais. In: Sociologia e antropologia. Trad. Mauro W. B. de Almeida. São Paulo: EPU/EDUSP, 1974. 2 v.

RANCIÈRE, Jacques. $O$ mestre ignorante: cinco lições sobre a emancipação intelectual. Trad. Lílian do Valle. Belo Horizonte: Autêntica, 2002.

SEM AUTOR, Pisa: desempenho do Brasil piora em leitura e 'empaca' em ciências. Disponível em: < https://educacao.uol.com.br/noticias/2013/12/03/pisa-desempenhodo-brasil-piora-em-leitura-e-empaca-em-ciencias.htm >. Acesso emः 13 abr. 2016. SARTRE, Jean-Paul. O que é subjetividade? Trad. Estela dos Santos Abreu. Rio de Janeiro: Nova Fronteira, 2015.

VÁZQUEZ, Adolfo Sánchez. Filosofia da Praxis. Trad.Luiz Fernando Cardoso. Rio de Janeiro: Paz e Terra, 1977. 